\title{
PENYULUHAN, PENGETAHUAN DAN SIKAP PASANGAN USIA SUBUR TENTANG INPEKSI VISUAL ASAM ASETAT (IVA) DI KELURAHAN BIROBULI
}

\author{
Reflection, Knowledge and Attitude of Lush Age Couples \\ About Visual Acetic Acid Inpection in Kelurahan Birobuli
}

\author{
Taqwin $^{1}$, Sumiaty ${ }^{2}$, Kartini Lasman $^{3}$ \\ ${ }^{1,2,3}$ Poltekkes Kemenkes Palu \\ (taqwin.sahe78@gmail.com, 081358617089)
}

\begin{abstract}
ABSTRAK
Kanker leher rahim merupakan masalah kesehatan serius. Cakupan pemeriksaan Inpeksi Visual Asam Asetat (IVA) di Birobuli masih rendah dari target sasaran, dari 13.474 orang hanya $8,7 \%$ target yang tercapai. Tujuan penelitian untuk mengetahui pengaruh penyuluhan IVA terhadap pengetahuan dan sikap pasangan usia subur di Kelurahan Birobuli. Metode penelitian pre experimental design dengan pendekatan pretest-posttest design. Populasi adalah seluruh pasangan usia subur yang bertempat tinggal di Kelurahan Birobuli sebanyak 432 orang. Teknik pengambilan sampel purposive sampling sebanyak 40 orang. Data dianalisis dengan univariat dan bivariat uji-t berpasangan. Hasil penelitian menunjukkan sebelum diberikan penyuluhan pengetahuan baik sebanyak 32,5\%, pengetahuan kurang sebanyak $67,5 \%$. Setelah diberikan penyuluhan, pengetahuan baik meningkat menjadi $92,5 \%$ dan pengetahuan kurang menurun 7,5\%. Hasil uji t berpasangan diperoleh nilai Mean Rank $-2,675$ dan nilai $\mathrm{p}=0,000$. Sebelum diberikan penyuluhan sikap positif sebanyak $35 \%$ dan sikap negatif sebanyak $65 \%$, setelah diberikan penyuluhan sikap positif meingkat menjadi $87,5 \%$ dan sikap negatif menurun menjadi 12,5\%. Hasil uji t berpasangan diperoleh nilai Mean Rank -7,450 dan nilai $\mathrm{p}=0,000$. Kesimpulan adalah ada pengaruh penyuluhan IVA terhadap pengetahuan dan sikap pasangan usia subur di Kelurahan Birobuli. Disarankan kepada Bidan di Puskesmas Birobuli untuk meningkatkan perannya sebagai edukator, sehingga pengetahuan dan sikap pasangan usia subur tentang IVA mengalami peningkatan dan kasus kanker serviks dapat dicegah secara dini.
\end{abstract}

Kata kunci : Pengetahuan, Sikap, penyuluhan, dan IVA

\begin{abstract}
Cervical cancer is a serious health problem. The coverage of Visual Acetate Acid (IVA) inspection at Birobuli was still lower than the target, of 13,474 people only $8.7 \%$ of the target was achieved. The aim of the study was to determine the effect of IVA counseling on the knowledge and attitudes of fertile age couples in Birobuli Village. The research method is pre-experimental design with a pretest-posttest design approach. The population is all fertile couples who reside in Birobuli Sub-District as many as 432 people. The purposive sampling technique is 40 people. Data were analyzed by univariate and bivariate t-test in pairs. The results of the study showed that before being given information on good knowledge as much as 32.5\%, there was less knowledge as much as $67.5 \%$. After being given counseling, good knowledge increased to 92.5\% and less knowledge decreased by 7.5\%. The results of paired t test obtained a Mean Rank value of -2.675 and a value of $p=0.000$. Before being given positive attitude counseling as much as $35 \%$ and negative attitudes as much as $65 \%$, after being given positive attitude counseling increased to $87.5 \%$ and negative attitudes decreased to $12.5 \%$. The results of the paired t test obtained a Mean Rank value of -7.450 and a value of $p=0.000$. The conclusion is that there is an influence of IVA counseling on knowledge and attitudes of fertile age couples in Birobuli Village. It is recommended to Midwives at Birobuli Health Center to increase their role as educators, so that the knowledge and attitudes of fertile couples about IVA increase and cervical cancer cases can be prevented early.
\end{abstract}

Keywords : Knowledge, attitude, counseling, and IVA 


\section{PENDAHULUAN}

Berdasarkan WHO kanker sebagai penyebab kematian nomor 2 di dunia sebesar 13\% setelah penyakit kardiovaskular. Setiap tahun 12 juta orang di dunia menderita kanker dan 7,6 juta diantaranya meninggal dunia. Terlebih untuk negara miskin dan berkembang kejadiannya akan lebih cepat ${ }^{(1)}$. Tanpa penatalaksanaan yang adekuat, diperkirakan Setiap 1 menit muncul 1 kasus baru dan setiap 2 menit meninggal 1 orang perempuan karena kanker serviks ${ }^{(2)}$.

Dinas Kesehatan Provinsi Sulawesi Tengah mencatat setiap tahunnya terdapat peningkatan positif IVA atau mengarah pada diagnosis serviks pra-kanker. Pada tahun 2014 terdapat 35 kasus dari 2.841 orang, pada tahun 2015 meningkat 22 kasus dari 2.187 orang, tahun 2016 sebanyak 47 kasus dari 1.666 orang. Tahun 2017 sebanyak 171 kasus dari 6.443 orang $^{(3)}$. Data Dinas Kesehatan Kota Palu untuk Puskesmas Birobuli dengan jumlah kasus 10 kasus dari 150 yang datang melakukan pemeriksaan ${ }^{(4)}$. Rendahnya minat ibu dalam melakukan tes IVA dipengaruhi oleh beberapa faktor. Faktor yang memengaruhi adalah ketidaktahuan informasi, budaya tabu, budaya malu dan kurangnya pendekatan yang dilakukan oleh petugas kesehatan. Bidan dituntut mampu melakukan pendekatan melalui konseling dalam memecahkan masalah kesehatan $\mathrm{ibu}^{(5)}$.

Pengetahuan sangat berpengaruh terhadap perilaku seseorang, sebagian besar penderita kanker datang sudah dalam stadium lanjut sehingga sulit lagi disembuhkan. Faktor penyebab tingginya angka kejadian kanker di Indonesia salah satunya adalah kesadaran perempuan yang sudah pernah melakukan hubungan seksual untuk melakukan deteksi dini masih rendah. Deteksi dini merupakan kunci upaya penyembuhan semua jenis kanker. Pentingnya deteksi dini dilakukan untuk mengurangi prevalensi jumlah penderita dan untuk mencegah terjadinya kondisi kanker pada stadium lanjut. Metode untuk melakukan deteksi dini kanker serviks adalah dengan pap smear, selain metode ini ada metode lain yang dapat digunakan yaitu dengan metode IVA test, Thin Prep, dan kolposkopi ${ }^{(6)}$. Sebaliknya pengetahuan yang baik pada Ibu PUS akan membentuk sikap positif terhadap deteksi dini kanker serviks $^{(7)}$. Sikap juga merupakan faktor yang dapat memengaruhi kesadaran seseorang. Sikap yang baik akan menimbulkan respon yang baik pula terhadap deteksi dini kanker serviks $^{(8)}$.

Wawancara peneliti terhadap bidan koordinator di Puskesmas Birobuli, pencapaian test IVA lebih banyak berdasarkan hasil penjaringan dilapangan. Bidan juga mengatakan masih rendahnya minat ibu dalam ikut serta dalam test IVA. Ibu lebih banyak takut atau malu jika dilakukan pemeriksaan IVA. Berdasarkan hal tersebut di atas, mendorong peneliti untuk melakukan penelitian tentang "Pengaruh penyuluhan IVA terhadap pengetahuan dan sikap pasangan usia subur di Kelurahan Birobuli”. 


\section{METODE PENELITIAN}

Jenis penelitian yang digunakan yaitu Pre experimental design dengan pendekatan pretest-posttest design. Penelitian telah dilaksanakan pada tanggal 2-30 April 2018 di Kelurahan Birobuli Kota Palu. Populasi dalam penelitian ini adalah seluruh PUS yang bertempat tinggal di Kelurahan Birobuli yang berjumlah 432 orang dan sampel sebnayak 40 orang. Teknik pengambilan sampel dalam penelitian ini adalah purposive sampling. Kriteria inklusi dalam penelitian ini adalah: Pasangan usia subur di Kelurahan Birobuli Pasangan usia subur yang memiliki pasangan sah secara agama dan undang-undang. Bersedia menjadi responden.

Penyuluhan IVA: Pemberian informasi dengan cara ceramah dengan bantuan leaflet pada masyarakat tentang IVA mulai dari pengertian, manfaat, tujuan dari pemeriksaan IVA.

Pengetahuan: Segala sesuatu yang di ketahui dan dipahami oleh PUS tentang IVA mulai dari pengertian, manfaat, tujuan dari pemeriksaan IVA Baik, jika skor jawaban responden $>50 \%$ Kurang, jika skor jawaban $\leq$ 50\%. Sikap: Tanggapan ibu tentang Pemeriksaan IVA. Positif, jika skor jawaban responden $>24,67$ pre test dan post test 27,55 Negatif, jika skor jawaban $\leq 24,67$ pre test dan post test 27,55 .

\section{HASIL}

Responden berumur 20-35 Tahun yaitu sebanyak 33 responden $(82,5 \%)$ dan umur yang paling sedikit adalah umur $>35$ tahun yaitu sebanyak 2 responden (5\%). Pendidikan responden yang paling banyak adalah pendidikan menengah (SMA) sebanyak 19 responen $(47,5 \%)$ dan pendidikan yang paling sedikit adalah pendidikan tinggi (>D1) sebanyak 8 responden (20\%). Pekerjaan yang paling banyak adalah IRT sebanyak 29 responen $(72,5 \%)$ dan pendidikan yang paling sedikit adalah PNS sebanyak 3 responden $(7,5 \%)$.

Tabel 1. Karakteristik Pasangan Usia Sun Kelurahan Birobuli Tahun 2018

\begin{tabular}{lcc}
\hline Karakteristik & f & \% \\
\hline Umur Ibu Hamil & & \\
< 20 Tahun & 5 & 12,5 \\
20-35 Tahun & 33 & 82,5 \\
> 35 Tahun & 2 & 5,0 \\
Pendidikan & & \\
Dasar & 13 & 32,5 \\
Menengah & 19 & 47,5 \\
Tinggi & 8 & 20,0 \\
Pekerjaan & & \\
IRT & 29 & 72,5 \\
PNS & 3 & 7,5 \\
Swasta & 8 & 20,0 \\
\hline Jumlah & $\mathbf{4 0}$ & $\mathbf{1 0 0}$ \\
\hline Sumber : Data Primer, 2018 &
\end{tabular}

Tabel 2. Distribusi Pengetahuan dan Sikap Pasangan Usia Subur Sebelum dan Sesudah Diberikan Penyuluhan IVA di Kelurahan Birobuli Tahun 2018

\begin{tabular}{|c|c|c|c|c|}
\hline \multirow[t]{2}{*}{ Variabel } & \multicolumn{2}{|c|}{$\begin{array}{c}\text { Sebelum } \\
\text { Diberikan } \\
\text { penyuluhan }\end{array}$} & \multicolumn{2}{|c|}{$\begin{array}{c}\text { Setelah } \\
\text { Diberikan } \\
\text { Penyuluhan }\end{array}$} \\
\hline & f & $\%$ & $\mathbf{F}$ & $\%$ \\
\hline \multicolumn{5}{|l|}{ Pengetahuan } \\
\hline Baik & 13 & 32,5 & 37 & 92,5 \\
\hline Kurang & 27 & 67,5 & 3 & 7,5 \\
\hline \multicolumn{5}{|l|}{ Sikap } \\
\hline Positif & 14 & 35 & 35 & 87,5 \\
\hline Negatif & 26 & 65 & 5 & 12,5 \\
\hline Jumlah & 40 & 100 & 40 & 100 \\
\hline
\end{tabular}

Sumber : Data Primer, 2018 
Tabel 2 menunjukkan bahwa sebelum diberikan penyuluhan pengetahuan baik sebanyak 13 responden (32,5\%), pengetahuan kurang sebanyak 27 responden $(67,5 \%)$. Setelah diberikan penyuluhan pengetahuan baik sebanyak 37 responden $(92,5 \%)$ dan pengetahuan kurang sebanyak 3 responden (7,5\%). sebelum diberikan penyuluhan sikap positif sebanyak 14 responden (35\%), sikap negatif sebanyak 26 responden (65\%). Setelah diberikan penyuluhan sikap positif sebanyak 35 responden $(87,5 \%)$ dan sikap negatif sebanyak 5 responden $(12,5 \%)$.

Tabel 3. Pengaruh Penyuluhan IVA Terhadap Pengetahuan dan Sikap Pasangan Usia Subur di Kelurahan Birobuli Tahun 2018

\begin{tabular}{lcc}
\hline Pre test-post test & Mean Rank & p-value \\
\hline $\begin{array}{l}\text { Pengetahuan pre } \\
\text { dan pengetahuan } \\
\text { post penyuluhan }\end{array}$ & $-2,675$ & 0,000 \\
\hline $\begin{array}{l}\text { Sikap pre dan } \\
\text { sikap post } \\
\text { penyuluhan }\end{array}$ & $-7,450$ & 0,000 \\
\hline
\end{tabular}

Sumber : Data Primer, 2018

Tabel 3 menunjukkan hasil uji-t berpasangan diperoleh nilai Mean Rank -2,675 dan nilai $\mathrm{p}=0,000 \quad(\mathrm{P} \leq 0,05)$, dengan demikian secara statistik ada pengaruh penyuluhan IVA terhadap pengetahuan pasangan usia subur di Kelurahan Birobuli. Demikian juga dengan sikap diperoleh nilai Mean Rank -7,450 dan nilai $\mathrm{p}=0,000(P \leq 0,05)$, yang berarti ada pengaruh penyuluhan IVA terhadap sikap pasangan usia subur di Kelurahan Birobuli.

\section{PEMBAHASAN}

Pengaruh penyuluhan IVA terhadap pengetahuan pasangan usia subur di Kelurahan Birobuli

Penyuluhan IVA berpengaruh terhadap pengetahuan pasangan usia subur di Kelurahan Birobuli. Responden telah mengetahui pemeriksaan IVA merupakan cara sederhana dalam deteksi kanker leher rahim, pemeriksaan pemeriksaan IVA biayanya murah dan terjangkau, sebelum dilakukan pemeriksaan tes IVA pasien akan mendapatkan informasi tentang prosedur penatalaksanaan IVA dan hasil dari uji tes IVA akan dijaga kerahasiaanya. Responden yang berpengetahuan baik sebagian besar berpendidikan menengah dan tinggi. Semakin tinggi pendidikan membuat pola berpikir menjadi berkembang, sehingga pemahaman tentang pemeriksaan IVA menjadi baik. Dilihat dari pekerjaan pengetahuan yang baik sebagian besar adalah ibu rumah tangga, dimana ibu rumah tangga lebih banyak memiliki waktu dalam mencari informasi. Dilihat dari umur, usia 20-35 tahun merupakan masa yang paling produktif. Semakin bertambah usia responden maka kematangan emosial semakin baik sehingga kemampuan dalam memahami masalah IVA semakin baik pula.

Responden yang pengetahuannya kurang baik, kurang memahami tentang skrining IVA memberikan hasil segera, responden beranggapan hasil IVA sampai seminggu, responden beranggapan petugas kesehatan yang hanya bisa melakukan 
pemeriksaan IVA adalah dokter Obgyn, padahal pada kenyataannya bidan terlatih dapat melakukannya, responden tidak mengetahui bahwa untuk melakukan skrining tes IVA ini 12 jam sebelumnya tidak melakukan hubungan seksual.

Hal tersebut diatas sesuai dengan teori Notoatmodjo $^{(9)}$ yang menyebutkan bahwa pengetahuan atau kognitif merupakan domain yang sangat penting untuk terbentuknya tindakan seseorang, ada beberapa faktor yang mempengaruhi perilaku, diantaranya adalah usia, pendidikan, lingkungan pekerjaan, dan pengalaman.

Sesuai yang dikemukakan Nursalam ${ }^{(10)}$ bahwa semakin tinggi tingkat pendidikan seseorang makin mudah untuk menerima informasi sehingga dengan informasi yang banyak makin banyak pula pengetahuan yang akan didapat. Sejalan dengan Mubarak ${ }^{(11)}$ pendidikan berarti bimbingan yang diberikan seseorang kepada orang lain terhadap sesuatu hal agar mereka dapat memahami. Tidak dapat dipungkiri bahwa makin tinggi pendidikan seseorang semakin mudah pula mereka menerima informasi, dan pada akhirnya makin banyak pula pengetahuan yang dimilikinya. Sebaliknya jika tingkat pendidikan seseorang rendah, akan menghambat perkembangan perilaku seseorang terhadap penerimaan, informasi dan nilai-nilai yang baru diperkenalkan.

Penelitian di Bali oleh Dewi Sri et al $l^{(12)}$ menyatakan bahwa WUS yang memiliki tingkat pengetahuan yang tinggi tentang pemeriksaan IVA memiliki kemungkinan perilaku periksa IVA 28,34 kali lebih besar dari pada WUS dengan tingkat pengetahuan rendah. Sedangkan WUS yang mempunyai Sikap baik memiliki kemungkinan perilaku periksa IVA 28,77 kali lebih besar dari pada WUS dengan sikap kurang.

Penelitian yang dilakukan oleh Kusuma \& Utami ${ }^{(13)}$ menyatakan bahwa yang berhubungan dengan kunjungan pemeriksaan IVA adalah tingkat pengetahuan sedangkan yang tidak hubungan dengan kunjungan pemeriksaan IVA adalah jarak ketempat pelayanan kesehatan dan dukungan suami.

Penelitian Silvia \& Muliati $^{(14)}$ menyatakan bahwa tidak ada hubungan antara umur, status ekonomi dan paritas dengan pemeriksaan IVA. Ada hubungan yang signifikan antara pendidikan, pengetahuan, sikap dengan pemeriksaan IVA.

\section{Pengaruh penyuluhan IVA terhadap sikap pasangan usia subur di Kelurahan Birobuli}

Penyuluhan IVA berpengaruh terhadap sikap pasangan usia subur di Kelurahan Birobuli. Responden yang memiliki sikap positif disebabkan karena dalam keluarga atau kerabat terdekat responden pernah melakukan pemeriksaan IVA, sehingga responden lebih yakin dalam melakukan pemeriksaan. Hasil jawaban kuesioner menunjukkan sikap positif, ditunjukkan dengan pemeriksaan IVA tidak akan merugikan responden, adanya kesadaran bahwa pemeriksaan IVA diperlukan untuk seluruh wanita yang telah menikah responden sudah banyak yang yakin bahwa penyakit 
kanker serviks dapat dicegah melalui pemeriksaan IVA.

Sebelum diberikan penyuluhan sikap positif lebih banyak mengenai melakukan pemeriksaan IVA lebih awal dapat memperpanjang umur karena kita mencegah terjadinya kanker dan responden bersedia untuk mengikuti program pemeriksaan IVA di Puskesmas Birobuli.

Sikap negatif lebih banyak dari pada sikap positif sebelum diberikan penyuluhan. Sikap negatif lebih banyak mengenai responden tidak bersedia untuk mengikuti program pemeriksaan IVA di Puskesmas Birobuli, responden malu untuk melakukan pemeriksaan IVA di Puskesmas Birobuli.

Hasil penelitian ini sesuai dengan pendapat Notoatmodjo ${ }^{(9)}$ yaitu suatu sikap belum otomatis terwujud dalam suatu tindakan. Untuk mewujudkan sikap menjadi suatu perbuatan nyata diperlukan faktor pendukung atau suatu kondisi yang memungkinkan, antara lain fasilitas. Disamping faktor fasilitas, juga diperlukan faktor dukungan dari pihak lain.

Bertolak belakang dengan penelitian Hidayati $^{(15)}$ yang menyatakan bawah tidak ada hubungan yang signifikan antara sikap ibu tentang kanker serviks dengan perilaku pemeriksaan IVA di Puskesmas. Hal itu dikarenakan sikap dapat terwujud dalam situasi saat itu. Responden yang memiliki sikap positif dengan pemeriksaan IVA belum tentu memiliki keinginan untuk periksa IVA. Sikap responden terhadap kanker leher rahim dalam penelitian Safrina ${ }^{(16)}$ sebagian besar memiliki sikap positif $(65,09 \%)$, artinya sejalan dengan pengetahuan yang baik, maka sikap juga cenderung positif.

\section{KESIMPULAN DAN SARAN}

Ada pengaruh penyuluhan IVA terhadap pengetahuan dan sikap pasangan usia subur di Kelurahan Birobuli. Diharapkan bagi bidan di Puskesmas Birobuli, lebih meningkatkan perannya sebagai edukator, sehingga pengetahuan dan sikap pasangan usia subur tentang Inspeksi Visual Asam Asetat (IVA) mengalami peningkatan dan kasus kanker serviks bisa lebih dicegah.

\section{UCAPAN TERIMA KASIH}

Terima kasih kepada Direktur Poltekkes Kemenkes Palu, Kepala Puskesmas Birobuli dan seluruh responden penelitian ini.

\section{DAFTAR PUSTAKA}

1. Departemen Kesehatan RI. Program Nasional Gerakan Pencegahan dan Deteksi Dini Kanker Leher Rahim dan Kanker Payudara [Internet]. 2015 p. 1-47. Available from: http://www.p2ptm.kemkes.go.id/dokumen$\mathrm{p} 2 \mathrm{ptm} /$ panduan-program-nasional-gerakanpencegahan-dan-deteksi-dini-kanker-kankerleher-rahim-dan-kanker-payudara-21-april2015

2. Arum, SP. Stop Kanker Serviks: Panduan Bagi Wanita Untuk Mengenal, Mencegah dan Mengobati. 2015 p.1-268 Buku Pintar: Yogyakarta

3. Dinas Kesehatan Provinsi Sulawesi Tengah, 2017. Profil Kesehatan Provinsi Sulawesi Tengah.

4. Dinkes Kota Palu, 2017. Profil Dinas Kesehatan Kota Palu, Palu

5. Kemenkes RI. 2016. Modul Pelatihan Pelayanan Kesehatan Peduli Remaja (PKPR) Bagi Konselor Sebaya. Direktorat Jendral Bina Gizi dan Kesehatan Anak. 
6. Smart. 2013. Kanker Organ Reproduksi. Yogyakarta: Darul Hikmah

7. Rahayu, 2015. Asuhan Ibu Dengan Kanker Serviks. Salemba Medika: Jakarta.

8. Martini, 2013. Memahami Kesehatan Reproduksi Wanita. Jakarta: EGC

9. Notoatmodjo, 2012, Metodologi Penelitian Kesehatan. Rineka Cipta. Jakarta

10. Nursalam. 2013. Manajemen Keperawatan Dan Aplikasinya. EGC: Jakarta

11. Mubarak. 2012. Promosi Kesehatan Untuk Kebidanan. salemba Medika: Jakarta

12. Dewi Sri, Nunuk Suryani \& Murdani, 2013. Hubungan tingkat pengetahuan dan sikap wanita usia subur dengan pemeriksaan Inspeksi Visual Asetat (IVA) di Puskesmas Buleleng I. Jurnal Magister Kedokteran Keluarga Vol.1, No.1 2013 p57-66, http:/jurnal.pasca.uns.ac.id.

13. Kusuma dan Utami. 2016. Faktor-faktor yang mempengaruhi kunjungan pemeriksaan IVA di Puskesmas Banguntapan 2 Bantul. Fakultas Ilmu Kesehatan Universitas Aisyah. Yogyakarta. http://digilib.unisayogya.ac.id.

14. Silvia dan Muliati. Hubungan Karakteristik Pengetahuan dan Sikap dengan pemeriksaan Inspeksi Visual Asam Asetat (IVA) pada ibu pasagan usia subur di Puskesmas Talise, Volume 1 Nomor 2, Desember 2017 http://ejournal.binausadabali.ac.id.

15. Hidayati. 2017. Hubungan Pengetahuan Dan Sikap Ibu Tentang Kanker Serviks Dengan Perilaku Pemeriksaan IVA di Puskesmas Melati 1. http://digilib.unisayogya.ac.id.

16. Safrina. 2016. Hubungan Pengetahuan Sikap dan Perilaku Wanita Dewasa Muda Terhadap Kanker Leher Rahim. Fakultas Kedokteran Universitas Syiah Kuala, Banda Aceh. Indonesia. http://mediapsi.ub.ac.id. 